\title{
More published full-time researchers, early career researchers, clinician-researchers and graduate students unite to call for actions against the pseudoscientific claim that chiropractic care boosts immunity
}

\author{
Pierre Côtét ${ }^{1,2,3^{*}}$ (D) André Bussières ${ }^{4,5}$, J. David Cassidy ${ }^{3}$, Jan Hartvigsen ${ }^{6,7}$, Greg N. Kawchuk ${ }^{8}$, \\ Charlotte Leboeuf-Yde ${ }^{9}$, Silvano Mior ${ }^{2,10}$ and Michael Schneider ${ }^{11,12}$
}

On May 4, 2020 we published a commentary entitled: " $A$ united statement of the global chiropractic research community against the pseudoscientific claim that chiropractic care boosts immunity" [1]. Our paper generated significant interest within the research community and several individuals contacted us to ask whether they could co-sign the commentary. We believe that it is important for members of the research community to formally add their voice to this important public health discussion.

On May 6, 2020, the authors of the commentary were asked to inform their networks of the opportunity to add co-signatories. This included an invitation made on social media. Specifically, we invited full-time researchers, early career researchers, clinician-researchers, graduate students and individuals who have published in the peer-reviewed literature during the course of their career to add their name to the list of co-signatories [2].

On May 20, 2020, 71 new individuals had responded to our call. Of those, 52 are affiliated with academic or research institutions, 15 are in private practice, two have retired and one is currently inactive. Therefore, 224 signatories are now calling for "regulatory authorities and professional leaders to take robust political and

\footnotetext{
* Correspondence: pierre.cote@uoit.ca

${ }^{1}$ Faculty of Health Sciences, Ontario Tech University, Oshawa, Canada ${ }^{2}$ Centre for Disability Prevention and Rehabilitation at Ontario Tech University and CMCC, Oshawa, Canada

Full list of author information is available at the end of the article
}

regulatory action against those claiming that chiropractic adjustments have a clinical impact on the immune system."

It is likely that other individuals in the research community would like to add their signatures to the commentary. Therefore, a webpage has been created (https://nikkb.dk/table/cmt-signatories/) to display the names of all signatories, and provide the opportunity to those who qualify (publication in the peer reviewed literature) to add their names to the list.
Acknowledgements
Signatoriesł.
\# The views and opinions expressed herein are those solely of the authors and may not represent the views of their institution.
1. Jon Adams, University of Technology Sydney, Sydney, Australia
2. Knut Andersen, Private practice, Norway
3. Sasha Aspinall, Murdoch University, Perth, Australia
4. Pierre Boucher, Université du Québec à Trois-Rivières, Trois-Rivières,
Canada
5. Jonny Branney, Bournemouth University, Bournemouth, UK
6. Alexander Breen, AECC University College, Bournemouth, UK
7. Danica Brousseau, Université du Québec à Trois-Rivières, Trois-Rivières, Canada
8. Christian Calvert, Private Practice, Sweden
9. Edward Cambridge, Private practice, Canada
10. Joel P. Carmichael, University of Colorado School of Medicine, Aurora,
Colorado
11. Keith Charlton, Central Queensland University, Brisbane, Australia
12. Chadwick Chung, Canadian Memorial Chiropractic College, Toronto,
Canada
13. Gaelan Connell, Ontario Tech University, Oshawa, Canada
14. Sophia da Silva-Oolup, Canadian Memorial Chiropractic College, Toronto, Canada
15. Laura Davies, Private practice, UK
16. Christopher deGraauw, Canadian Memorial Chiropractic College, Toronto, Canada 
17. Felipe C.K. Duarte, Canadian Memorial Chiropractic College, Toronto, Canada

18. Martha Funabashi, Canadian Memorial Chiropractic College, Toronto, Canada

19. Matthew F. Funk, University of Bridgeport, Bridgeport, USA

20. Anne Marie Gausel, Stavanger University Hospital, Stavanger, Norway

21. Geoff Gelley, University of Manitoba, Winnipeg, Manitoba

22. Darrin Germann, Canadian Memorial Chiropractic College, Toronto,

Canada

23. Dominic Giuliano, Canadian Memorial Chiropractic College, Toronto, Canada

24. Lindsay Gorrell, University of Calgary, Calgary, Canada

25. Chris Grant, Private practice, Canada

26. Alexander Grier, Private practice, Canada

27. Francois Hains, Private practice, Canada

28. Léonie Hofstetter, Balgrist University Hospital, Zurich, Switzerland

29. Michelle Holmes, AECC University College, Bournemouth, UK

30. Scott Howitt, Canadian Memorial Chiropractic College, Toronto, Canada

31. Mohsen Kazemi, Canadian Memorial Chiropractic College, Toronto, Canada

32. Stuart Kinsinger, New York Chiropractic College, Seneca Falls, USA

33. Robert Kitchen, Retired, Canada

34. Carolina Kolberg, Federal University of Rio Grande do Sul, Porto Alegre, Brazil

35. Olivier Lanlo, Institut Franco-Européen de Chiropraxie, Ivry-sur-Seine, France

36. Robert A Leach, Private Practice, US

37. Jocelyn Lemire, Université du Québec à Trois-Rivières, Trois-Rivières,

Canada

38. Gordon McMorland, Private practice, Canada

39. Christine Meckamalil, Canadian Memorial Chiropractic College, Toronto, Canada

40. Jani Mikkonen, University of Eastern Finland, Kuopio and Joensuu, Finland

41. Dale Mierau, Retired, Saskatoon, Canada

42. Brad Muir, Canadian Memorial Chiropractic College, Toronto, Canada

43. Craig F. Nelson American Specialty Health, Minneapolis, USA

44. Richard Nicol, Geneva, Switzerland

45. Kirsten Olesen. Private practice, Canada

46. Per J. Palmgren, Karolinska Institutet, Solna, Sweden

47. Efrosini Papaconstantinou, Ontario Tech University, Oshawa, Canada

48. Caroline Poulin, Université du Québec à Trois-Rivières, Trois-Rivières, Canada,

49. Aaron Anthony Puhl, Private practice, Canada

50. Jairus Quesnele, Northern Ontario School of Medicine, Sudbury, Canada

51. Christine Reinhart, Private practice, Canada

52. Nadia Richer, Université du Québec à Trois-Rivières, Trois-Rivières, Canada,

53. John J. Riva, McMaster University, Hamilton, Canada

54. Jacqueline Rix, European Academy of Chiropractic, Hampton Hill, UK

55. Marc Sanders, AECC University College, Bournemouth, UK

56. Ann-Christin Sannes, The National Institute of Occupational Health in Norway

57. J Keith Simpson, Murdoch University, Perth, Australia

58. Guy Sovak, Canadian Memorial Chiropractic College, Toronto, Canada

59 Peter Stilwell, McGill University, Canada

60. Igor Steiman, Canadian Memorial Chiropractic College, Toronto, Canada

61. Matthew Stevens, The National Research Centre for the Working

Environment, Copenhagen, Denmark

62. Eric St-Onge, Private practice, Canada

63. Peter Tuchin, Private practice, Australia

64. Taylor Tuff, Canadian Memorial Chiropractic College, Toronto, Canada

65. Daphne To, Canadian Memorial Chiropractic College, Toronto, Canada

66. Simon Wang, Canadian Memorial Chiropractic College, Toronto, Canada

67. Carol Ann Weis, Canadian Memorial Chiropractic College, Toronto, Canada

68. Patrick Welsh, Private practice, Canada

69. Arnold Wong, The Hong Kong Polytechnic University, Hong Kong

70. Shari Wynd, Texas Chiropractic College, Pasadena, USA

71. Ken Young, University of Central Lancashire, England

\section{Authors' contributions}

All authors (Pierre Côté, André Bussières, J. David Cassidy, Jan Hartvigsen, Greg N. Kawchuk, Charlotte Leboeuf-Yde, Silvano Mior, Mike Schneider) developed, wrote, edited and proofread the commentary. All signatories reviewed the commentary and endorsed its content.

\section{Funding}

No funding was obtained for this commentary.

\section{Availability of data and materials \\ Not applicable.}

\section{Ethics approval and consent to participate}

Not applicable.

\section{Consent for publication}

Not applicable.

\section{Competing interests}

PC reports research grants unrelated to this work from Aviva Canada Canadian Institutes of Health Research-Canada Research Chair Program, Canadian chiropractic Association, Canadian Chiropractic Research Foundation, College of Chiropractors of British Columbia, Et liv i bevegelse" (ELIB), French Chiropractic Association, Financial Services Commission of Ontario, Ontario Ministry of Finance, Ontario Trillium Foundation; travel expenditures unrelated to this work from Griffith University - Whiplash Symposium 2017, Eurospine, Southern Denmark University, Institut Franco-Europeen de Chiropraxie, Karolinska Institutet, North American Spine Society, University of QuebecTrois-Rivieres, University of Zurich, World Federation of Chiropractic; fees medical-legal expertise from the Canadian Chiropractic Protective Association. He is the Chair of the World Federation of Chiropractic Research Disability and Rehabilitation Committee. AB reports research grants unrelated to this work from University of Quebec-Trois-Rivieres, McGill University, Centre de recherche interdisciplinaire en réadaptation du Montréal métropolitain, Canadian Institutes of Health Research; fees medical-legal expertise from the Canadian Chiropractic Protective Association. GNK reports active research grants unrelated to this work from The Natural Sciences and Engineering Research, The National Institutes of Health, The Alberta Spine Foundation, The American Orthotic and Prosthetic Association, The New Frontiers in Research Fund and the Canadian Chiropractic Research Foundation. Travel expenditures unrelated to this work in the past year include Kiropraktik i Sverige Live, Et liv i bevegelse" (ELIB), the Nordic Institute of Chiropractic and Clinical Biomechanics, The American Chiropractic Association, The National Institutes of Health, The British Columbia Chiropractic Association, and The World Federation of Chiropractic. He is the Chair of the World Federation of Chiropractic Research Council. Fees for medical-legal expertise unrelated to this work from the Canadian Chiropractic Protective Association. JH reports that he holds multiple research grants from Danish and international funding agencies and charities. He has received coverage of travel expenditures from multiple sources internationally in connection with speaking engagements. Within the past year he has received speaking fees from Parker Seminars and Novartis. He is member of the World Federation of Chiropractic Research Council. SM reports research grants unrelated to this work from Ontario Chiropractic Association, Canadian Chiropractic Association, and Canadian Chiropractic Research Foundation. MS reports support from research grants unrelated to this work from the National Institutes of Health, Patient Centered Outcomes Research Institute, University of Pittsburgh and NCMIC Foundation; honoraria from NCMIC speaker's bureau; fees from medico-legal consulting services. JDC and CLY declare that they have no competing interests.

\section{Author details}

${ }^{1}$ Faculty of Health Sciences, Ontario Tech University, Oshawa, Canada. ${ }^{2}$ Centre for Disability Prevention and Rehabilitation at Ontario Tech University and CMCC, Oshawa, Canada. ${ }^{3}$ Division of Epidemiology, Dalla Lana School of Public Health, University of Toronto, Toronto, Canada. ${ }^{4}$ Département chiropratique, Université du Québec à Trois-Rivières, Trois-Rivières, Canada. ${ }^{5}$ School of Physical and Occupational Therapy, Faculty of Medicine McGill University, Montreal, Canada. ${ }^{6}$ Department of Sports Science and Clinical Biomechanics, University of Southern Denmark, Odense, Denmark. ${ }^{7}$ Nordic Institute of Chiropractic and Clinical Biomechanics, Odense, Denmark. ${ }^{8}$ Faculty of Rehabilitation Medicine, University of Alberta, Edmonton, Canada. ${ }^{9}$ Institute for Regional Health Research, University of Southern Denmark, Odense, Denmark. ${ }^{10}$ Canadian Memorial Chiropractic College, Toronto, Canada. ${ }^{11}$ School of Health and Rehabilitation Sciences, University of Pittsburgh, Pittsburgh, USA. ${ }^{12}$ Clinical and Translational Science Institute, University of Pittsburgh, Pittsburgh, USA. 
Received: 22 May 2020 Accepted: 1 July 2020

Published online: 20 July 2020

\section{Rerefences}

1. Côté P, Bussières A, Cassidy JD, et al. A united statement of the global chiropractic research community against the pseudoscientific claim that chiropractic care boosts immunity. Chiropr Man Therap. 2020;28:21. https:// doi.org/10.1186/s12998-020-00312-x.

2. Kawchuck G. https://twitter.com/GNK1/status/1258000331704635394?s=20.

\section{Publisher's Note}

Springer Nature remains neutral with regard to jurisdictional claims in published maps and institutional affiliations.

Ready to submit your research? Choose BMC and benefit from:

- fast, convenient online submission

- thorough peer review by experienced researchers in your field

- rapid publication on acceptance

- support for research data, including large and complex data types

- gold Open Access which fosters wider collaboration and increased citations

- maximum visibility for your research: over $100 \mathrm{M}$ website views per year

At $\mathrm{BMC}$, research is always in progress. 